\section{Curricula Influence College Student Knowledge and Attitudes Regarding Invasive Species}

\author{
Tina M. Waliczek ${ }^{1,5,8}$, Kathryn M. Parsley ${ }^{2,6}$, Paula S. Williamson ${ }^{3}$, \\ and Florence M. Oxley ${ }^{4,7}$
}

AdDitional INDEX wORDs. active learning, invasive species education, hands-on education, factor analysis

\begin{abstract}
SUMMARY. Negative impacts from invasive species present a global problem.
Consequently, invasive species biology has emerged as an important subdiscipline of conservation biology. One of the goals of invasive species biology is to educate the public about impacts and potential control of invasive species. The purpose of this study was to determine if a lecture, a lecture and laboratory learning model, or both influence college student learning gains and whether increase in knowledge results in changes in attitudes about invasive species. A pre- and posttest instrument that measured knowledge and attitudes of invasive species was administered to several different classes of students at a university and community college. One group of students received a lecture and laboratory curriculum between the pre- and posttest (the lecture and laboratory treatment group). A second group of students received a lecture between the pre- and posttest (the lecture-only treatment group) and a third group received no instruction between tests (the control group). The lecture was in the form of an electronic presentation, whereas the laboratory curriculum included a case study, a visual aid, and a scavenger hunt to educate students about examples of invasive plant and animal species. In all classes and groups, there were at least 2 weeks between administering the pre- and posttest. Results showed that the control group scores were not different between the pre- and posttest. However, both the lecture-only and the lecture and laboratory treatment groups had scores that changed after receiving the curricula. In addition, there was an effect of curricula on student learning for the three conditions. The differences between the group that received no curricula vs. the two that did indicated that the curricula were effective teaching interventions to help students become more educated about invasive species.
\end{abstract}

$\mathrm{V}$ ery few ecosystems in the world are completely free of introduced species, and an increasing proportion of habitats is becoming dominated by them (Pysek and Richardson, 2010). Invasive species decrease species diversity (McGeoch et al., 2010), have negative economic impact (Pimentel et al., 2005), and threaten human health (Mack et al., 2000). Recognition of threats posed

Funding for this study was provided from the U.S Department of Agriculture Animal and Plant Health Inspection Service grant program.

${ }^{1}$ Department of Agriculture, Texas State University, San Marcos, TX 78666

${ }^{2}$ Department of Biology, The University of Memphis, Memphis, TN 38152

${ }^{3}$ Department of Biology, University Distinguished Professor of Biology, Texas State University, San Marcos, TX 78666

${ }^{4}$ Department of Biology, Austin Community College, Austin, TX 78785

${ }^{5}$ Professor of Horticulture.

${ }^{6}$ Graduate Student.

${ }^{7}$ Associate Professor of Biology.

${ }^{8}$ Corresponding author. E-mail: tcl0@txstate.edu.

https://doi.org/10.21273/HORTTECH03979-18 by invasive species has led to increasing pressure to control or eradicate them (Mack et al., 2000). Yet, control and eradication can become controversial.

Bertolino and Genovesi (2003) noted the impact public opinion has on success of invasive species management, citing failure of a plan to eradicate the invasive American gray squirrel (Sciurus carolinensis) from Italy due to public outcry from an animal rights group. Larson et al. (2011) considered the social pillar critical to the success of invasive species management plans and suggested oration and building support with a broad range of stakeholders, as well as increasing community education. Obstacles impeding invasive species management would likely be alleviated, given a well-informed public (Bertolino and Genovesi, 2003).

Vanderhoeven et al. (2011) suggested well-designed educational programs targeting particular groups could be effective tools to teach the public about invasive species. People focusing efforts on increasing collab- who had prior knowledge of invasive species eradication programs and who were also members of conservation organizations showed greater levels of support for invasive control programs (Bremner and Park, 2007; Oxley et al., 2016). Invasive species education at various levels of learning was examined (Waliczek et al., 2017). Yue et al. (2012) found that in marketing native vs. invasive species, educational labeling on plant material regarding the potential invasiveness of species would not necessarily change purchasing habits of typical consumers.

Educational programs have been put into action at the elementary school level to help increase awareness of invasive species and their impacts (Farmer et al., 2007). High schools have also implemented various teaching strategies in environmental science courses to address invasive species (Baumgartner and Zabin, 2008; DiEnno and Hilton, 2005). Oxley et al. (2016) found adults who had not received as much college education knew less about invasive species and were less likely to be involved in environmental organizations that could inform them about invasives. Undergraduate- and graduate-level coursework at $94 \mathrm{Ca}$ nadian universities was reviewed and education regarding invasive species was found lacking (Smith et al., 2011), leading the authors to call for incorporating invasive species into the university curricula.

A study by Waliczek et al. (2017) found a large gap in student knowledge about invasives, citing that college students did not feel informed or educated about invasive species. Yet, the study also found that students rated college classes as highly reliable sources of information about invasives, second only to environmental organizations (Waliczek et al., 2017). The authors pointed out the need to incorporate invasive species biology into college curricula (Waliczek et al., 2017). The purpose of this study was to determine if a lecture, a lecture and laboratory learning model, or both influence college student learning gains and whether increases in knowledge result in changes in attitudes about invasive species.

\section{Materials and methods}

An exemption request (EXP2015T8055334) for this research 
was approved by the Texas State University Institutional Review Board. An instrument was developed to measure students' knowledge of invasive species and their attitudes toward them using information obtained from the Texas Invasives (2017), the Texas Parks and Wildlife Department (2017), the U.S. Fish and Wildlife Service (2017), and a similar study instrument (Oxley et al., 2016). The instrument consisted of a pre- and a posttest, which were identical and included Likert scale items and multiple choice questions. A panel of experts with backgrounds from biology and horticulture who had experience in studying native and exotic plants and animals reviewed the instrument to determine validity. Demographic data including age, gender identity, ethnicity, and class rank were also collected from respondents.

INSTRUMENT KNOWLEDGE QUESTIONS. Fifteen multiple choice questions were used to assess knowledge of invasive species (Table 1). Examples of knowledge questions included the following "How many invasive species occur in the U.S.?" "Which of the following invasive animal species was unintentionally introduced into the continental U.S.?" and "Which of the following is an example of an invasive plant found in Texas?" Answers included an option to select "I don't know" (Table 1). Correct answers scored one point and incorrect answers, including "I don't know," did not receive a point. There was a possible perfect score of 15 points, with higher scores indicating more knowledge.

INSTRUMENT ATTITUDE ITEMS. Multiple choice questions and statements were used to assess student attitudes toward invasive species ( $\mathrm{Ta}$ bles 2-5). The statements were ranked responses using a five-point Likert scale, with answers ranging from 1 indicating the participant strongly disagreed with the statement to 5 indicating the participant strongly agreed with the statement. Statements were reverse coded as necessary for data analysis to keep higher scores associated with more positive responses.

INSTRUMENT ADMINISTRATION. Pre- and posttest knowledge and attitude instruments were administered to students enrolled at Texas State University (San Marcos, TX) and Austin Community College (Austin,
TX). At least 2 weeks elapsed between administration of the tests. Only researchers administered the tests and an incentive of extra credit points was offered to those who agreed to participate. Survey length was such that, on average, students spent 10-15 min completing each test.

SAMPLE AND GROUPS. There were three groups of participants. The control group $(n=50)$ received no instruction between pre- and posttests and consisted of students enrolled in Biology Fundamentals, Human Physiology, and Introduction to Anatomy and Physiology classes at Austin Community College. The lecture treatment group $(n=$ 105 ) received a lecture between tests and consisted of students enrolled in Modern Biology II, Woody Plants, and Organic Gardening classes at Texas State University. Students in the lecture and laboratory treatment group $(n=42)$ received a lecture and laboratory curricula between tests and were enrolled in the Economic Botany class at Texas State University.

Curriculum. The curricula delivered to students between pre- and posttests included information on invasive plants and animals. Topics such as defining an invasive species, means of intentional and unintentional introduction of invasive species, economic impact, how and to which agencies to report an invasive species when spotted, and biological characteristics of invasives were included. Content was drawn from the Texas Invasives (2017), Texas Parks and Wildlife Department (2017), and U. S. Fish and Wildlife Service (2017) and included locally, regionally, and nationally relevant material, and historical as well as present-day examples. The lecture portion of the curricula was delivered as an electronic (Powerpoint; Microsoft, Redmond, WA) presentation. Identical electronic presentations were shown to the lecture group and the lecture and laboratory group.

The laboratory curriculum, delivered exclusively to the lecture and laboratory group, included several pedagogical techniques to help students understand invasive plant and insect species including a case study, scavenger hunt, and visual aid chart. The case study adhered to standards set forth by the National Center for Case Study Teaching in Science
(2017). The case study scenario presented two plant species that students were to identify as native or invasive. Students explained the rationale used to make the determination. Students were also asked to identify appropriate agencies or organizations to report invasive species encountered. The scavenger hunt led students on a walk to find invasive species on campus. The visual aid chart demonstrated identification of invasive insects that damage agricultural crops by using mouthparts and leaf damage characteristics.

Data ANALYsis. Reliability of the knowledge portion of the instrument was determined using Cronbach's alpha (Gall et al., 2006). The instrument was found to be reliable $(\alpha=$ $0.804)$. A repeated measures analysis of variance (ANOVA) was used to determine if pre- and posttest scores were different for each group, whereas an independent samples $t$ test was conducted to compare posttest knowledge scores between the lecture and lecture and laboratory treatment groups.

Paired $t$ tests and frequency counts compared answers between the pre- and posttest for each treatment group on the following attitude questions: "Which of the following methods do you believe would be the best to control an invasive animal species?" "Which of the following methods do you believe would be the best to control an invasive plant species?" Exploratory factor analysis determined which factor(s), if any, the Likert scale attitude items were addressing. Any factor identified was named, and average scores on the items for that factor for each participant were computed. Afterward, a repeated measures ANOVA was used to determine differences in factor scores among the three groups. For each factor, reliability was calculated using Cronbach's alpha. For any Likert scale items not loading onto a factor, repeated measures ANOVAs were used to determine changes in answers to these questions between pre- and posttests. For those ANOVAs shown to have differences, pretest scores were compared using independent samples $t$ tests. If the pretest scores were not different, the process was repeated for posttest scores to determine if the type of treatment had an effect on posttest attitude scores. 


\section{Teaching Methods}

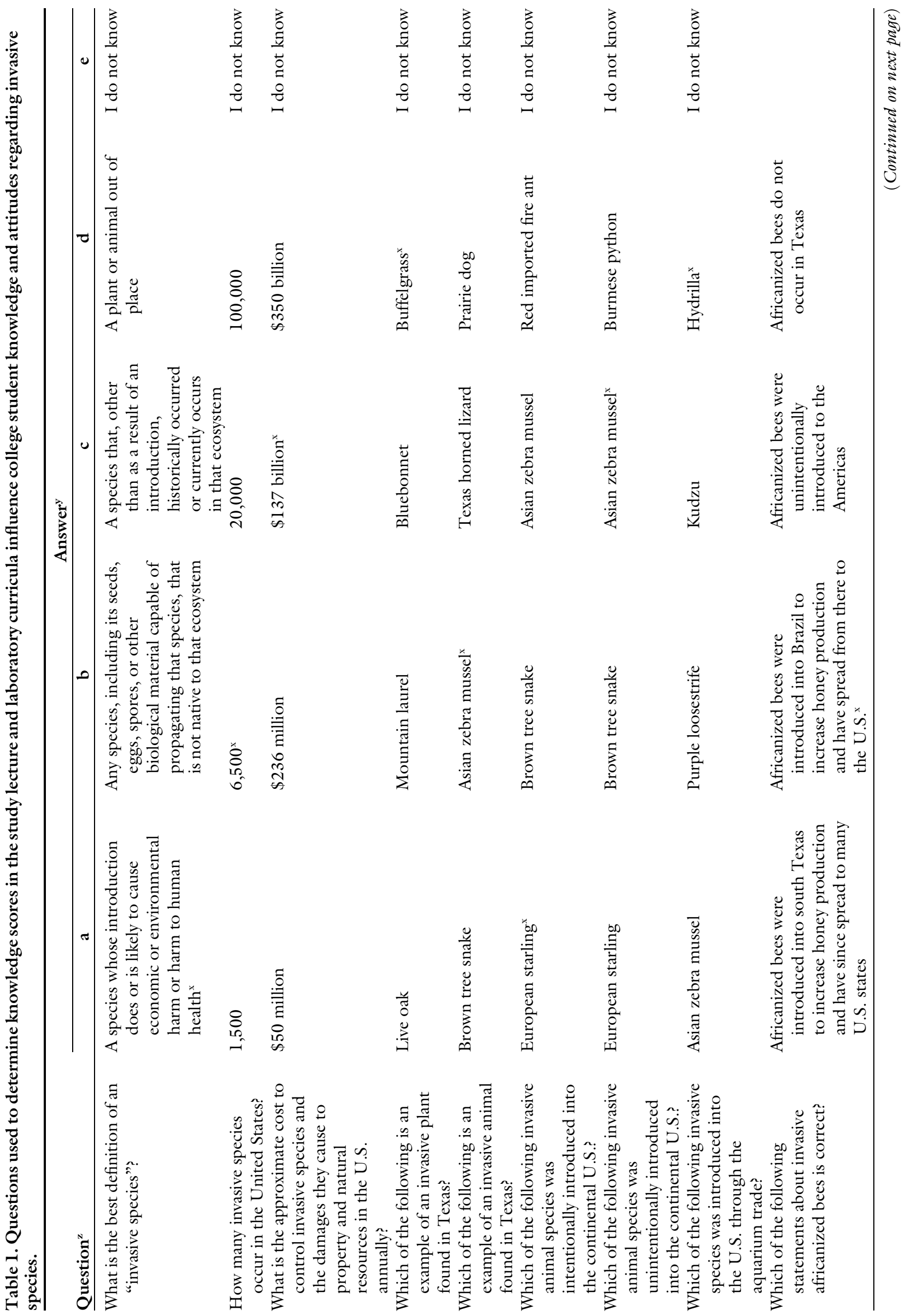




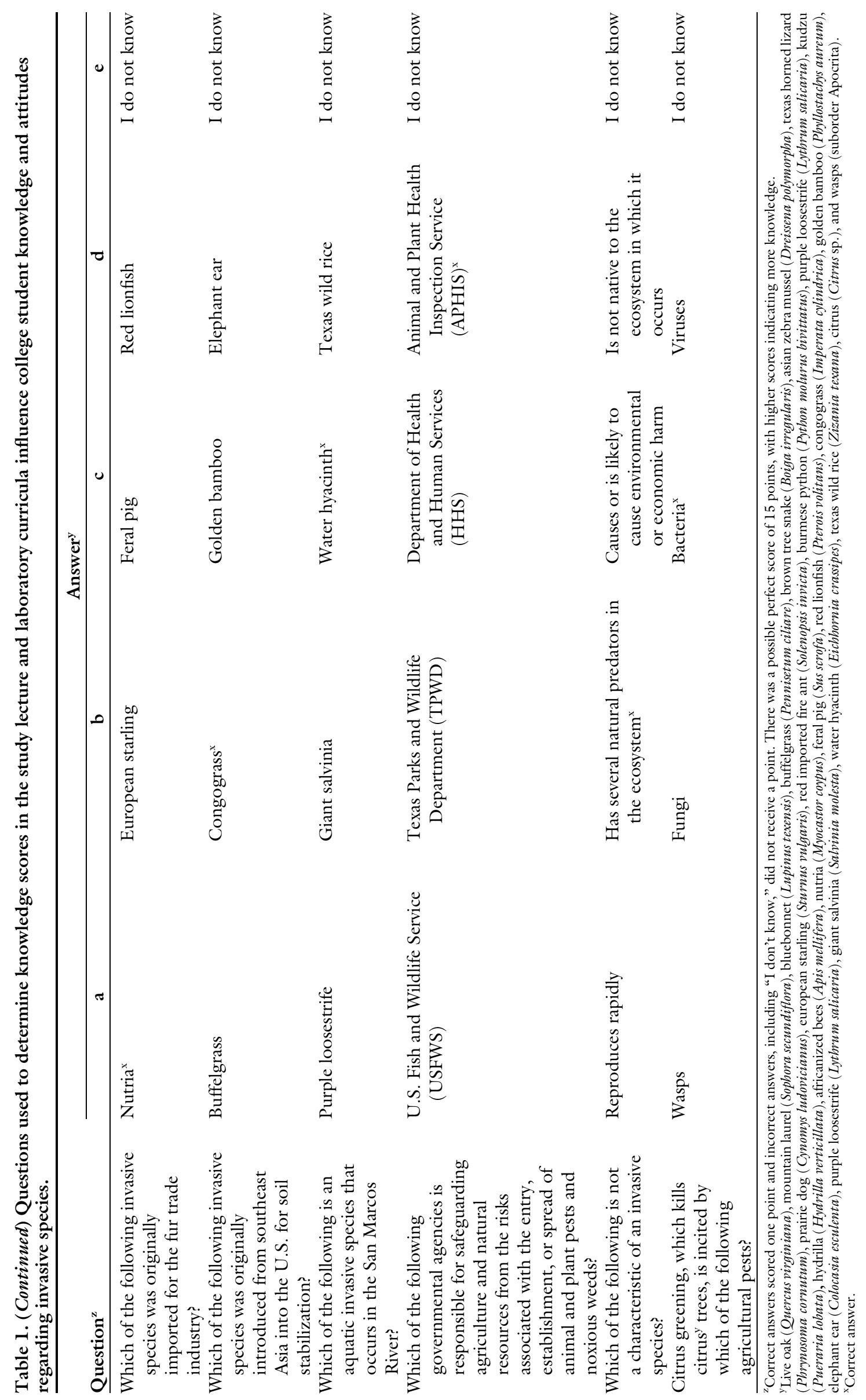

Hortlechnology · August 2018 28(4) 
Table 2. Paired $t$ test and frequency comparisons of responses for the control, lecture-only, and lecture and laboratory treatment groups to the question "Which of the following methods do you believe would be best to control an invasive animal species?" on the pre- and posttest in the study lecture and laboratory curricula influence college student knowledge and attitudes regarding invasive species.

\begin{tabular}{|c|c|c|c|c|c|c|c|}
\hline Group & $N$ & Method & Pretest $[$ no. $(\%)]$ & Posttest [no. (\%)] & df & $t$ & $P$ \\
\hline \multirow[t]{4}{*}{ Control } & 50 & Shooting & $1(2)$ & $7(14)$ & 49 & 0.109 & 0.914 \\
\hline & & Poisoning & $1(2)$ & $0(0)$ & & & \\
\hline & & Take no action & $2(4)$ & $0(0)$ & & & \\
\hline & & I do not know & $16(32)$ & $22(44)$ & & & \\
\hline \multirow[t]{3}{*}{ Lecture } & 105 & Shooting & $3(3)$ & $26(25)$ & 104 & 5.086 & $<0.001 *$ \\
\hline & & Take no action & $5(5)$ & $4(4)$ & & & \\
\hline & & I do not know & $16(15)$ & $4(4)$ & & & \\
\hline \multirow[t]{3}{*}{ Lecture and laboratory } & 42 & Shooting & $5(12)$ & $13(31)$ & 41 & 4.173 & $<0.001^{*}$ \\
\hline & & Poisoning & $3(7)$ & $2(5)$ & & & \\
\hline & & Trapping and relocating & $28(67)$ & $27(64)$ & & & \\
\hline
\end{tabular}

Table 3. Paired $t$ test and frequency comparisons of responses for the control, lecture-only, and lecture and laboratory treatment groups to the question "Which of the following methods do you believe would be best to control an invasive plant species?" on the pre- and posttest in each group in the study lecture and laboratory curricula influence college student knowledge and attitudes regarding invasive species.

\begin{tabular}{|c|c|c|c|c|c|c|c|}
\hline Group & $N$ & Method & Pretest [no. (\%)] & Posttest [no. (\%)] & df & $t$ & $P$ \\
\hline & & Manual removal & $14(28)$ & $12(24)$ & & & \\
\hline & & Take no action & $1(2)$ & $1(2)$ & & & \\
\hline & & I do not know & $23(46)$ & $29(58)$ & & & \\
\hline \multirow[t]{3}{*}{ Lecture } & 105 & Herbicides & $15(14)$ & $20(19)$ & 104 & 5.242 & $<0.001^{*}$ \\
\hline & & Take no action & $7(7)$ & $4(4)$ & & & \\
\hline & & I do not know & $35(33)$ & $8(8)$ & & & \\
\hline \multirow[t]{3}{*}{ Lecture and laboratory } & 42 & Herbicides & $7(17)$ & $16(38)$ & 41 & 1.432 & 0.160 \\
\hline & & Manual removal & $27(64)$ & $15(36)$ & & & \\
\hline & & Dredging & $4(9)$ & $10(24)$ & & & \\
\hline
\end{tabular}

\section{Results}

A total of 197 students completed both the pre- and posttests. Demographic comparisons of control vs. treatment groups were made using ANOVA and some differences were found. Overall, there were more female participants compared with male participants in the study. The control group was statistically different with more females proportionate to males compared with the treatment groups $(P=0.002)$, but the treatment groups were similar to one another [ control group $88 \%$ ( 44 females) and $12 \%$ (6 males), lecture group 61\% (64 females) and 39\%
(41 males), and lecture and laboratory group $64.3 \%$ (27 females) and $35.7 \%$ ( 15 males)].

Most participants were in the 18-34 years age range overall [control group $82 \%$ (41), lecture group $96.2 \%$ (101), and lecture and laboratory group $100 \%(42)$ ], reflecting typical age ranges for most university students (Texas State University Institutional Research, 2017). The control group was statistically different from the treatment groups, with the control group being slightly older $(P=0.001)$. However, the treatment groups were similar to one another. Most were sophomores in the control $[56 \%(28)]$ and lecture groups [30.5\%
(32)], whereas most students were juniors in the lecture and laboratory group [95.2\% (40)].

No statistical differences were found in comparisons of the students in the control vs. treatment groups among ethnic groups $(P=0.525)$. Students were predominately Caucasian [control group 42\% (21), lecture group $43.8 \%$ (46), and lecture and laboratory group $38.1 \%(16)]$ and Hispanic [control group 36\% (18), lecture group $38 \%(40)$, and lecture and laboratory group 38.1\% (16)]. This was also reflective of the ethnic backgrounds served at Texas State University (Texas State University Institutional Research, 2017). Because 
Table 4. Results of an exploratory factor analysis indicating correlations and communality based on principal axis factoring for seven items from the invasive species knowledge and attitudes instrument in the study lecture and laboratory curricula influence college student knowledge and attitudes regarding invasive species.

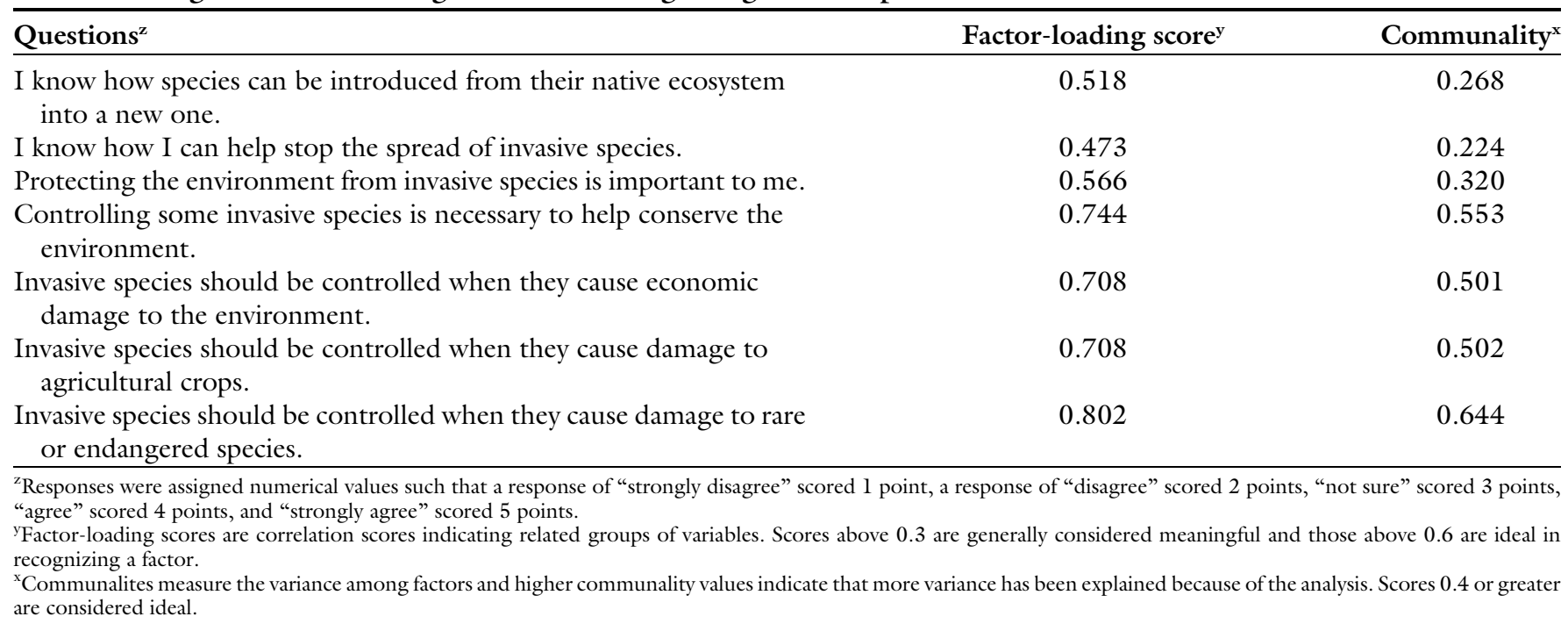

Table 5. Pre- and posttest scores for the three Likert items from the invasive species knowledge and attitudes instrument which were unrelated to other factors in a factor analysis in the study lecture and laboratory curricula influence college student knowledge and attitudes regarding invasive species.

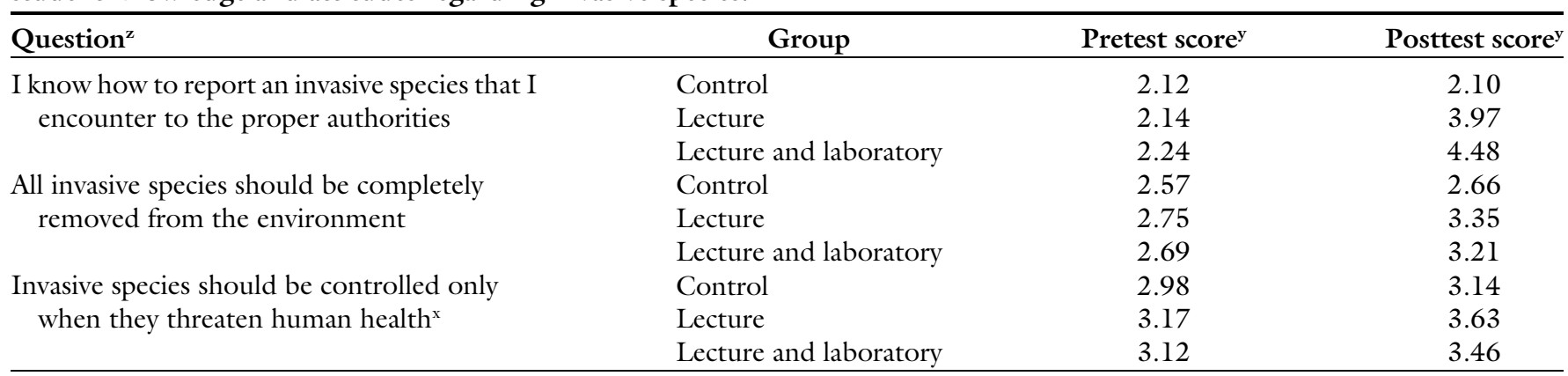

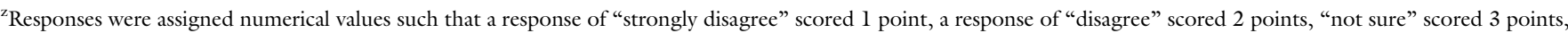
"agree" scored 4 points, and "strongly agree" scored 5 points.

"Higher scores indicate a more positive knowledge or attitude.

"Indicates that the numerical value assigned to responses for this question were reverse coded such that a response of "strongly disagree" scored 5 points, "disagree" scored 4 points," "slightly disagree" scored 4 points, "not sure" scored 3 points, "agree" scored 2 points, and "strongly agree" scored 1 point.

of the demographic differences noted in the samples drawn of convenience at each of the institutions, results of this study are suitable for baseline reporting rather than for generalizing to other populations.

KNOWLEDGE OF INVASIVE SPECIES. Of a possible score of 15 on the knowledge instrument used in the study, the control group scored a mean of 1.50 on the pretest and 1.70 on the posttest. The mean knowledge score for the lecture treatment group was 3.90 on the pretest and 8.02 on the posttest, an increase of 4.12 points. The lecture and laboratory treatment group had a mean score of 3.88 on the pretest and 9.62 on the posttest, an increase of 5.74 points on knowledge. The repeated measures ANOVA indicated that the groups were different in regard to change in knowledge scores. There was an effect of type of treatment on pre- and posttest scores [Wilks' lambda $=0.625 ; \mathrm{F}(2194)=58.25$, $P<0.001]$. The control group did not improve their knowledge scores from the pretest to the posttest. Although pretest scores did not differ significantly in the lecture vs. the lecture and laboratory groups, the independent samples $t$ test indicated a difference in posttest knowledge scores for lecture $($ mean $=8.02, \mathrm{SD}=$ 3.24 ) vs. the lecture and laboratory treatment groups $[$ mean $=9.62, \mathrm{SD}=$ 1.75; $t(145)=-3.02, P<0.001]$. This difference was because of the lecture and laboratory group scoring better on the posttest compared with the lecture group.
INVASIVE SPECIES CONTROL METHODS. When asked the question "Which of the following do you believe would be the best to control an invasive animal species?," the most widely selected method was "trapping and relocating" on the pretest, with $60 \%$ (30) in the control group, $71 \%$ (75) in the lecture group, and $67 \%$ (28) in the lecture and laboratory group selecting this method (Table $2)$. "Trapping and relocating" was also the most widely selected method on the posttest, with $42 \%(21)$ in the control group, $62 \%(65)$ in the lecture group, and $64 \%$ (27) in the lecture and laboratory group selecting this method (Table 2). However, the number of students selecting this method decreased on the posttest as answers shifted to other responses. 
The number of students in the control group selecting "shooting" increased from $2 \%$ (1) on the pretest to $14 \%(7)$ on the posttest. The number of students selecting "shooting" also increased in the lecture group from $3 \%$ (3) on the pretest to $25 \%(26)$ on the posttest. In addition, an increase in the number of students selecting "shooting" on the posttest [31\% (13)] occurred in the lecture and laboratory group as compared with the pretest $[12 \%(5)]$ (Table 2).

In the control group, more students selected "I don't know" on the posttest $[44 \%(22)]$ compared with the pretest $[32 \%(16)]$. In the lecture group, 15\% (16) selected "I don't know" on the pretest, yet only $4 \%$ (4) selected this response on the posttest. "I don't know" was selected by $7 \%$ (3) of students in the lecture and laboratory group on the pretest, and no students selected this response on the posttest. Fewer students selected "take no action" on the posttest compared with the pretest in all three groups (Table 2 ).

Responses to the question "Which of the following do you believe would be the best to control an invasive plant species?" on the pre- and posttests indicated that a greater number of students in the control group selected, "I don't know" on the posttest [58\% (29)] compared with the pretest [46\% (23)] (Table 3). The number of students in the lecture group selecting "I don't know" in response to this question declined from the pretest $[33 \%$ (35)] to the posttest $[8 \%(8)]$. A decrease in the answer "I don't know" was also found in the lecture and laboratory group [pretest 5\% (2) and posttest $0 \%(0)]$.

In the lecture group, there was an increase in the acceptance of all methods to control invasive plant species after receiving the curriculum (Table 3 ). In the lecture and laboratory group, there was an increase in acceptance of dredging and herbicides as control methods, but a decrease in the number of students selecting manual removal to control invasive plants following receiving the curricula (Table 3 ). The control group scores showed no change between the pre- and posttest (Table 3 ).

LikerT atTitudinal ITEMs. An exploratory factor analysis to determine which Likert items on the attitude portion of the instrument were related to one another showed 7 of the 10 items were highly correlated and loaded onto a single factor, which was termed, "appreciating and understanding impacts of invasive species" (Table 4). The reliability was calculated for this attitude factor using Cronbach's alpha and was found to have an adequate level of reliability $(\alpha=0.823)$ (Gall et al., 2006). A repeated measures ANOVA revealed changes in the "appreciating and understanding impacts of invasive species" attitude factor. Scores for the attitude factor also increased $(P<$ 0.001 ) in both the lecture and the lecture and laboratory treatment groups after their respective treatments were administered (Table 5). Higher scores indicated greater appreciation and understanding of invasive species' impacts and the increase represented attitudinal change.

Three items did not load onto a factor and were analyzed separately (Table 6). For the item "I know how to report an invasive species that I encounter to the proper authorities," a repeated measures ANOVA indicated there was a difference in mean scores among the three groups in comparisons of the pre- vs. posttest [Table $6(P<0.001)]$. Both the lecture and lecture and laboratory treatment groups increased in their average scores, whereas the control group remained the same (Table 6). The lecture and laboratory treatment group did not have differences in pretest scores when compared with those of the lecture-only treatment group pretest scores $(P=0.586)$. However, differences were seen in the lecture and laboratory posttest scores when compared with those of the lecture-only group $[P<0.001$ (Table 6)].

For the item "All invasive species should be completely removed from the environment," the repeated measures ANOVA for this question also revealed a difference $(P=0.020)$ among the three groups (Table 6). Both treatment groups increased their mean scores for this question on the posttest, but the control group did not increase (Table 6).

For the item "Invasive species should be controlled only when they threaten human health," the ANOVA

Table 6. Repeated measures ANOVA for the three Likert items not loading onto a factor in the groups at pre- and posttest time points in the study of lecture and laboratory curricula influence college student knowledge and attitudes regarding invasive species.

\begin{tabular}{|c|c|c|c|c|c|}
\hline Question $^{\mathrm{z}}$ & Effect & MS & df & $\mathbf{F}$ & $P$ \\
\hline \multirow{3}{*}{$\begin{array}{l}\text { I know how to report an invasive species that I } \\
\text { encounter to the proper authorities }\end{array}$} & Time & 149.69 & 1 & 201.65 & $<0.001^{*}$ \\
\hline & Time $\mathrm{x}$ & & & & \\
\hline & Error & 0.74 & 192 & & \\
\hline \multirow{2}{*}{$\begin{array}{l}\text { All invasive species should be completely removed } \\
\text { from the environment }\end{array}$} & Time & 13.63 & 1 & 23.27 & $<0.001^{*}$ \\
\hline & Time $\mathrm{x}$ & & & & \\
\hline \multirow{4}{*}{$\begin{array}{l}\text { Invasive species should be controlled only when they } \\
\text { threaten human health }\end{array}$} & Time & 6.11 & 1 & 4.38 & 0.038 * \\
\hline & Time $\mathrm{x}$ & & & & \\
\hline & Treatment Group & 0.74 & 2 & 0.53 & 0.59 \\
\hline & Error & 1.40 & 191 & & \\
\hline
\end{tabular}

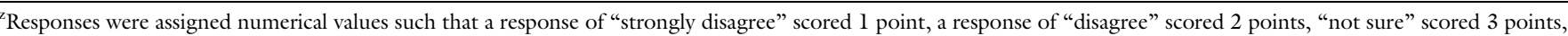
"agree" scored 4 points, and "strongly agree" scored 5 points.

"Indicates that the numerical value assigned to responses for this question were reverse coded such that a response of "strongly disagree" scored 5 points, "disagree" scored 4 points," "slightly disagree" scored 4 points, "not sure" scored 3 points, "agree" scored 2 points, and "strongly agree" scored 1 point.

${ }^{*}$ Statistically significant at $P \leq 0.05$. 
revealed there was no difference $(P=$ 0.592 ) among the three groups for this item between the pre- and posttest (Table 6). All three groups increased their agreement with this item on the posttest (Table 6).

\section{Discussion}

The college classroom has been suggested as useful for educating students about invasive species biology, although it has been underused (Smith et al., 2011; Waliczek et al., 2017). The curricula delivered to college students in this study were effective in increasing student knowledge about invasive species. Both the lecture and the lecture and laboratory treatment groups showed an improvement in knowledge following the learning intervention, whereas the control group not exposed to a curriculum did not exhibit an increase in knowledge scores. In addition, the lecture and laboratory group performed better on the posttest compared with the lecture group.

The laboratory has long been regarded as an essential part of learning science (Hofstein and Lunetta, 1982). Freedman (1997) also found being involved in a laboratory results in higher science proficiency and a better attitude toward science as a discipline. One of the seven principles for good practice in undergraduate education is emphasizing time on task (Chickering and Gamson, 1987). One possible explanation for the lecture and laboratory group exhibiting higher posttest knowledge scores compared with the lectureonly group is that they had more time on task. Since the lecture and laboratory group spent an additional $2 \mathrm{~h}$ learning about invasive species in the laboratory setting, the increased time on task may have resulted in higher knowledge scores. Given that Taraban et al. (2007) found active learningbased laboratory units can lead to enhanced content knowledge and process learning for students, the possibility exists to attribute higher knowledge scores found in the lecture and laboratory group to exposure to hands-on, active learning techniques in this laboratory curriculum. Active learning techniques are known to positively influence student learning outcomes (Freeman et al., 2014). Prince (2004) found that different techniques in active learning had different levels of effectiveness in improving student learning outcomes, but across the board, all techniques improved student achievement more when compared with the traditional lecture setting. Perhaps, the best explanation is that the combination of active learning techniques and time on task together led to increased performance by the lecture and laboratory treatment group in this study.

There was no change in attitude for the statement "I know how to report an invasive species that I encounter to the proper authorities" in the control group between pre- and posttest, but both treatment groups increased their agreement with this item on the posttest. This indicates that after receiving learning interventions, both treatment groups felt better prepared to report an invasive species to the proper authorities. Comparing treatment groups, the lecture and laboratory group's agreement was greater on this question on the posttest. This indicates receiving both curricula influenced attitudes to a greater extent when compared with receiving the lecture alone. The lecture portion of the curricula did include a segment on reporting invasive species, but the laboratory component of the curricula further emphasized appropriate methods to report invasive species. The additional reinforcement from the laboratory experience may explain the increased confidence found in the lecture and laboratory treatment group.

Although an increase in knowledge is an important outcome in this study, it is not a surprising result. The more noteworthy outcome is that increased knowledge was accompanied by attitudinal change. This study also found a shift in the attitude factor termed "appreciating and understanding the impacts of invasive species." Although the control group displayed virtually no change in attitude, both treatment groups increased their appreciation and understanding of the impacts of invasives following the learning interventions.

The curricula used in the study influenced student opinions and attitudes regarding control methods of invasive species. Paired $t$ tests and frequency counts of answers to the questions asking the best methods to control animal and plant invasive species revealed in both treatment groups the frequency of the answer "I don't know" decreased on the posttest, suggesting increased confidence in their knowledge of appropriate control methods. The answer "I don't know" actually increased on the posttest in the control group.

When considering methods to control invasive animal species, the most favored method in all three groups on both pre- and posttests was the nonlethal method of "trapping and relocating." However, all three groups showed an increase in respondents selecting "shooting" as an appropriate control method on the posttest as compared with the pretest. Shooting was presented in the curricula as an effective method to control nutria (Myocastor coypus), which might explain increased support for this control method in the two treatment groups. However, the shift in acceptance for "shooting" cannot be entirely attributed to the curricula because this response also increased in the control group. Attitudes toward lethal control methods tend to be value based and formed early on in life (Treves and Naughton-Treves, 2005), but results of our study indicate education may change attitudes, resulting in an informed public more accepting of lethal control methods.

Several authors suggest that negative attitudes toward invasive species control methods become obstacles to managing invasive species (Andreu et al., 2009; Bardsley and EdwardsJones, 2006; Marshall et al., 2011; Shine and Doody, 2011). Public education plays a vital role in developing positive attitudes and securing support for invasive species management (Bremner and Park, 2007; GarcíaLlorente et al., 2008; Oxley et al., 2016). Waliczek et al. (2016) pointed out that higher education can influence college students' attitudes toward environmental issues. This study further demonstrates that an invasive species curricula delivered at the college level is effective in changing student knowledge and attitudes toward invasives.

\section{Literature cited}

Andreu, J., M. Vila, and P.E. Hulme. 2009. An assessment of stakeholder perceptions and management of noxious alien plants in Spain. Environ. Mgt. 43:1244. 
Bardsley, D. and G. Edwards-Jones. 2006. Stakeholder's perceptions of the impacts of invasive exotic plant species in the Mediterranean region. GeoJournal 65:199-210.

Baumgartner, E. and C.J. Zabin. 2008. A case study of project-based instruction in the ninth grade: A semester-long study of intertidal biodiversity. Environ. Educ. Res. 14:97-114.

Bertolino, S. and P. Genovesi. 2003. Spread and attempted eradication of the grey squirrel (Sciurus carolinensis) in Italy, and consequences for the red squirrel (Sciurus vulgaris) in Eurasia. Biol. Conserv. 109:351-358.

Bremner, A. and K. Park. 2007. Public attitudes to the management of invasive non-native species in Scotland. Biol. Conserv. 139:306-314.

Chickering, A.W. and Z.F. Gamson. 1987. Seven principles for good practice in undergraduate education. Amer. Assn. Higher Educ. Bul. 3:7.

DiEnno, C.M. and S.C. Hilton. 2005. High school students' knowledge, attitudes, and levels of enjoyment of an environmental education unit on nonnative plants. J. Environ. Educ. 37:13-25.

Farmer, J., D. Knapp, and G.M. Benton. 2007. An elementary school environmental education field trip: Long-term effects on ecological and environmental knowledge and attitude development. J. Environ. Educ. 38:33-42.

Freeman, S., S.L. Eddy, M. McDonough, M.K. Smith, N. Okoroafor, H. Jordt, and M.P. Wenderoth. 2014. Active learning increases student performance in science, engineering, and mathematics. Proc. Natl. Acad. Sci. USA 111:8410-8415.

Freedman, M.P. 1997. Relationship among laboratory instruction, attitude toward science, and achievement in science knowledge. J. Res. Sci. Teach. 34:343-357.

Gall, M.D., W.R. Borg, and J.P. Gall. 2006. Educational research: An introduction. 8th ed. Allyn and Bacon, White Plains, NY.

García-Llorente, M., B. Martín-López, J. A. González, P. Alcorlo, and C. Montes. 2008. Social perceptions of the impacts and benefits of invasive alien species: Implications for management. Biol. Conserv. 141:2969-2983.

Hofstein, A. and V.N. Lunetta. 1982. The role of the laboratory in science teaching: Neglected aspects of research. Rev. Educ. Res. 52:201-217.
Larson, D.L., L. Phillips-Mao, G. Quiram, L. Sharpe, R. Stark, S. Sugita, and A. Weiler. 2011. A framework for sustainable invasive species management: Environmental, social, and economic objectives. J. Environ. Mgt. 92:14-22.

Mack, R.N., D. Simberloff, W.M. Lonsdale, H. Evans, M. Clout, and F.A. Bazzaz. 2000. Biotic invasions: Causes, epidemiology, global consequences, and control. Ecol. Appl. 10:689-710.

Marshall, N.A., M. Friedel, R.D. van Klinken, and A.C. Grice. 2011. Considering the social dimension of invasive species: The case of buffel grass. Environ. Sci. Policy 14:327-338.

McGeoch, M.A., S.H.M. Butchart, D. Spear, E. Marais, E.J. Kleynhans, A. Symes, J. Chanson, and M. Hoffmann. 2010. Global indicators of biological invasion: Species numbers, biodiversity impact and policy responses. Diversity and Distributions 16:95-108.

National Center for Case Study Teaching in Science. 2017. Teaching resources. 18 Jan. 2018 . <http://sciencecases.lib. buffalo.edu/cs $/>$.

Oxley, F.M., T.M. Waliczek, and P.S. Williamson. 2016. Stakeholder opinions on invasive species and their management in the San Marcos River. HortTechnology 26:514-521.

Pimentel, D., R. Zuniga, and D. Morrison. 2005. Update on the environmental and economic costs associated with alieninvasive species in the United States. Ecol. Econ. 52:273-288.

Prince, M. 2004. Does active learning work? A review of the research. J. Eng. Educ. 93:223-231.

Pysek, P. and D.M. Richardson. 2010 Invasive species, environmental change and management, and health. Mgt. Biol. Invasions 35:25-55.

Shine, R. and J.S. Doody. 2011. Invasive species control: Understanding conflicts between researchers and the general community. Front. Ecol. Environ. 9:400 406.

Smith, A.L., D.R. Bazely, and N.D. Yan. 2011. Missing the boat on invasive alien species: A review of post-secondary curricula in Canada. Can. J. High. Educ. 41:34-47.
Taraban, R., C. Box, R. Myers, R. Pollard, and C.W. Bowen. 2007. Effects of activelearning experiences on achievement, attitudes, and behaviors in high school biology. J. Res. Sci. Teach. 44:960-979.

Texas Invasives. 2017. What are invasive species? 18 Jan. 2018 . <http:// texasinvasives.org/il01/>.

Texas Parks and Wildlife Department. 2017. Exotic and invasive species. 18 Jan. 2018. <http://tpwd.texas.gov/huntwild/ wild/species/exotic/>.

Texas State University Institutional Research. 2017. University enrollment explorer, Who are they? 12 July 2017. <https://public.tableau.com/ views / TXSTEnrollmentExplorer/ Whoaret he y ? \% 3 A e m b e d =y \& \% 3AshowTabs=y\&\%3Adisplay_count $=$ no\& $\% 3$ AshowVizHome $=$ no $>$.

Treves, A. and L. Naughton-Treves. 2005. Evaluating lethal control in the management of human-wildlife conflict. Conserv. Biol. Ser. Cambridge 9:86-106.

U.S. Fish and Wildlife Service. 2017. What is an invasive species? 18 Jan. 2018. <https://www.fws.gov/invasives/>.

Vanderhoeven, S., J. Piqueray, M. Halford, G. Nulens, J. Vincke, and G. Mahy. 2011. Perception and understanding of invasive alien species issues by nature conservation and horticulture professionals in Belgium. Environ. Mgt. 47:425-442.

Waliczek, T., A. McFarland, and M. Holmes. 2016. The relationship between a campus composting program and environmental attitudes, environmental locus of control, compost knowledge, and compost attitudes of college students. HortTechnology 26:592-598.

Waliczek, T.M., P.S. Williamson, and F. M. Oxley. 2017. College student knowledge and perceptions of invasive species. HortTechnology 27:550-556.

Yue, C., T. Hurley, and N. Anderson. 2012. Heterogeneous consumer preferences for native and invasive plants: Evidence from experimental auctions. HortScience 47:1091-1095. 